\title{
Czech dysplasia, metatarsal type
}

INSERM

\section{Source}

INSERM. (1999). Orphanet: an online rare disease and orphan drug data base. Czech dysplasia, metatarsal type. ORPHA:137678

Czech dysplasia, metatarsal type is a form of skeletal dysplasia characterised by severe arthropathy beginning in childhood and hypoplasia/dysplasia of the third, fourth and/or fifth toes. 